This is an electronic reprint of the original article. This reprint may differ from the original in pagination and typographic detail.

Author(s): Karhu, Aino J.; Jämsä, Juho; Rautiainen, Mikko; Oilunkaniemi, Raija; Chivers, Tristram; Laitinen, Risto S.

Title: $\quad$ A Selenium-Nitrogen Chain with Selenium in Different Oxidation States

Year: $\quad 2017$

Version:

Please cite the original version:

Karhu, A. J., Jämsä, J., Rautiainen, M., Oilunkaniemi, R., Chivers, T., \& Laitinen, R. S. (2017). A Selenium-Nitrogen Chain with Selenium in Different Oxidation States. Zeitschrift für anorganische und allgemeine Chemie, 643(7), 495-500. https://doi.org/10.1002/zaac.201700031

All material supplied via JYX is protected by copyright and other intellectual property rights, and duplication or sale of all or part of any of the repository collections is not permitted, except that material may be duplicated by you for your research use or educational purposes in electronic or print form. You must obtain permission for any other use. Electronic or print copies may not be offered, whether for sale or otherwise to anyone who is not an authorised user. 


\title{
A Selenium-Nitrogen Chain with Selenium in Different Oxidation States
}

\author{
Aino J. Karhu, ${ }^{a}$ Juho Jämsä, ${ }^{a}$ J. Mikko Rautiainen, ${ }^{\text {a,b }}$ Raija Oilunkaniemi, ${ }^{\text {a }}$ Tristram Chivers, ${ }^{*, c}$ and
}

Risto S. Laitinen *,a

ABSTRACT. The reaction of $t \mathrm{BuNH}_{2}$ with a mixture of $\mathrm{SeCl}_{2}$ and $\mathrm{SeOCl}_{2}$ in a 6:2:1 molar ratio produces the novel selenium-nitrogen chain $\mathrm{ClSeN}(\mathrm{tBu}) \mathrm{Se}(\mathrm{O}) \mathrm{Cl}(4)$, in which the selenium atoms are in two different oxidation states, $\mathrm{Se} \mathrm{II}^{\mathrm{II}}$ and $\mathrm{Se}^{\mathrm{IV}}$. The crystal structure of 4 is compared with that of the related $\mathrm{Se}^{\mathrm{II}} / \mathrm{Se}^{\mathrm{II}}$ system $\mathrm{ClSeN}(t \mathrm{Bu}) \mathrm{SeCl}(\mathbf{1})$ and differences are attributed to hyperconjugative effects. The energetics of the formation of 4 via two different routes are elucidated by PBE0/def2-TZVPP calculations.

Supporting information for this article is available on the WWW under http://dx.doi.org/10.1002/zaac.201700031 or from the authors.

Keywords: Selenium(II)/Selenium(IV); Acyclic compound; Crystal structure; Hyperconjugation; Energy profiles

a. Laboratory of Inorganic Chemistry, Environmental and Chemical Engineering, University of Oulu, P. O. Box 3000, FI-90014 Oulu, Finland. E-mail: risto.laitinen@oulu.fi

b. Present address: Department of Chemistry, University of Jyväskylä, P. O. Box 35, FI40014, Finland

c. Department of Chemistry, University of Calgary, Calgary, AB, CanadaT2N 1N4. E-mail: chivers@ucalgary.ca 


\section{INTRODUCTION}

Although the chemistry of selenium-nitrogen heterocycles often parallels that of the sulfur-nitrogen analogues, $^{[1]}$ there are notable exceptions especially among $\mathrm{N}, \mathrm{Se}, \mathrm{Cl}$ species. For example, there is no selenium analogue of the six-membered ring $(\mathrm{NSCl})_{3}$, which is an important reagent in sulfur-nitrogen chemistry ${ }^{[1,2]}$ Conversely, although the acyclic cations $\mathrm{N}(E \mathrm{Cl})_{2}{ }^{+}$are known for $E=\mathrm{S}^{[3]}$ and $\mathrm{Se},{ }^{[4]}$ the cation $\mathrm{N}\left(\mathrm{SeCl}_{2}\right)_{2}{ }^{+[5]}$ and the anion $\mathrm{N}\left(\mathrm{SeCl}_{3}\right)_{2}{ }^{-[6]}$ are unique chalcogen-nitrogen species. This disparity is notably evident in the series of acyclic imidoselenium(II) chlorides $\mathrm{ClSe}[\mathrm{N}(t \mathrm{Bu}) \operatorname{Se}]_{n} \mathrm{Cl}[n=1(1), n=2(2), n=3$ (3) $],,^{[7-9]}$ for which no sulfur counterparts are known. We have recently isolated 1-3 and identified them as key intermediates in the formation of cyclic selenium imides of the type $(\operatorname{SeN} R)_{n}(n=3,4)$ or $\operatorname{Se}_{n}(\mathrm{~N} R)_{n-1}$ $(n=3,4)$ from the cyclocondensation reactions of $t \mathrm{BuNH}_{2}$ with in situ-generated $\mathrm{SeCl}_{2}{ }^{[10]}$ at various molar ratios. ${ }^{[7-9]}$ During the course of that work we isolated a few crystals of the novel selenium-nitrogen chain $\mathrm{ClSeN}(t \mathrm{Bu}) \mathrm{Se}(\mathrm{O}) \mathrm{Cl}(4)$ with selenium in two different oxidation states $\left(\mathrm{Se}^{\mathrm{II}}\right.$ and $\left.\mathrm{Se}^{\mathrm{IV}}\right)$.

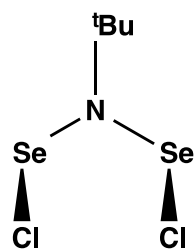

1<smiles>CC(C)CN([Se]Cl)[Se]N(CC(C)C)[Se]N([Se])[Se]Cl</smiles><smiles>CC(C)(C)N([Se]Cl)[Se]N([Se]Cl)[Se]Cl</smiles>

2<smiles>O=[Se](Cl)N([Ge]Cl)[Ge]Cl</smiles>

In the light of the obvious similarity between 1 and 4, we were interested in determining the effect of the oxygen substituent in $\mathbf{4}$ on the structure and properties of these acyclic compounds. In this contribution, with this goal in mind, we describe (a) a logical route to the synthesis of 4 in a good yield from the reaction of $t \mathrm{BuNH}_{2}$ with a mixture of $\mathrm{SeCl}_{2}$ and $\mathrm{SeOCl}_{2}$ in THF, (b) the multinuclear solution NMR spectra and single-crystal X-ray structure of 4, (c) an NBO (Natural Bond Orbital) analysis of hyperconjugative effects in 4 and 1, and (d) PBE0/def2-TZVPP calculations of the energetics of formation of 4 from $t \mathrm{BuNH}_{2}$ and either $\mathrm{SeCl}_{2}$ or $\mathrm{SeOCl}_{2}$ as the first step in the condensation process. 


\section{RESULTS AND DISCUSSION}

\section{Synthesis and NMR Spectra of $\mathrm{ClSeN}(t \mathrm{Bu}) \mathrm{Se}(\mathrm{O}) \mathrm{Cl}(4)$}

For the intentional synthesis of 4 we chose to use a mixture of $\mathrm{SeCl}_{2}$ and $\mathrm{SeOCl}_{2}$, as sources of $\mathrm{Se}^{\mathrm{II}}$ and $\mathrm{Se}^{\mathrm{IV}}$, respectively, in a reaction with $t \mathrm{BuNH}_{2}$ in THF. Although the stoichiometry shown in Equation (1) would appear to be the most appropriate for the generation of 4, the choice of the optimum $\mathrm{SeCl}_{2}: \mathrm{SeOCl}_{2}$ molar ratio for the synthesis of 4 is not straightforward owing to the facile disproportionation of $\mathrm{SeCl}_{2}$ into $\mathrm{SeCl}_{4}$ and $\mathrm{Se}_{2} \mathrm{Cl}_{2}{ }^{[10]} \mathrm{The}^{77} \mathrm{Se} \mathrm{NMR}$ spectra of various mixtures of $\mathrm{SeCl}_{2}$ and $\mathrm{SeOCl}_{2}$ in $\mathrm{THF}$ at room temperature showed that such solutions contain equimolar amounts of the two reagents only when the initial molar ratio is $2: 1$. In the light of this information a molar ratio of 2:1:6 for the reagents $\mathrm{SeCl}_{2}: \mathrm{SeOCl}_{2}: \mathrm{BuNH}_{2}$ was employed for the synthesis of 4 , which was isolated as air and thermally sensitive orange-yellow crystals in $54 \%$ yield. ${ }^{[11,12]}{ }^{77}$ Se NMR monitoring of the progress of reactions using different molar ratios in THF consistently revealed two resonances of equal intensity at 1447 and $1316 \mathrm{ppm}$ ascribed to compound 4 (vide infra); in all cases singlet resonances attributed to the presence of $\mathrm{ClSeN}(t \mathrm{Bu}) \mathrm{SeCl}(\mathbf{1})$ and the eight-membered ring $\mathrm{Se}_{4}(\mathrm{~N} t \mathrm{Bu})_{4}$ were also observed at 1806 and $1487 \mathrm{ppm}$, respectively. ${ }^{[7,13]}$

$$
\mathrm{SeCl}_{2}+\mathrm{SeOCl}_{2}+3 t \mathrm{BuNH}_{2} \rightarrow \mathrm{ClSeN}(t \mathrm{Bu}) \mathrm{Se}(\mathrm{O}) \mathrm{Cl}+2\left(t \mathrm{BuNH}_{3}\right) \mathrm{Cl}
$$

After recrystallization, the crystals of 4 were dissolved in $\left[\mathrm{D}_{8}\right]$ toluene. The ${ }^{1} \mathrm{H}$ NMR spectrum of 4 in $\left[\mathrm{D}_{8}\right]$ toluene shows a resonance at $\delta=1.29 \mathrm{ppm}$, and the ${ }^{13} \mathrm{C}\left\{{ }^{1} \mathrm{H}\right\}$ NMR spectrum exhibits two singlets at $\delta$ $=72.1$ and $31.3 \mathrm{ppm}$ consistent with a single $\mathrm{N} t \mathrm{Bu}$ environment. The ${ }^{77} \mathrm{Se} \mathrm{NMR}$ spectrum of the isolated crystals in toluene exhibits two resonances at 1435 and $1291 \mathrm{ppm}$ of equal intensities consistent with significantly different selenium environments. The former resonance is attributed to the more deshielded central $\mathrm{NSe}(=\mathrm{O}) \mathrm{Cl}$ unit, whereas the latter is assigned to the $\mathrm{NSeCl}$ environment. The calculated PBEO/def2-TZVPP ${ }^{77}$ Se chemical shifts of 4 using the approach described in Ref. [13] were 1349 and 1200 ppm, which, in view of the computational accuracy, are reasonably consistent with the experimental values of 1435 and $1291 \mathrm{ppm}$ in toluene.

\section{Crystal Structure and Hypeconjugative Interactions in $\mathrm{ClSeN}(\mathrm{tBu}) \mathrm{Se}(\mathrm{O}) \mathrm{Cl}(4)$}

The X-ray structural determination of 4 confirmed the acyclic structure with $\mathrm{Se}^{\mathrm{II}}$ and $\mathrm{Se}^{\mathrm{IV}}$ atoms. Crystal data and structure refinement details are presented in Table 1 . The asymmetric unit in 4 consists of two different molecules, one of which is disordered assuming two different orientations [s.o.f. 0.564(4) and 
$0.436(4)]$ for the more- and less-abundant orientations, respectively. The molecular structures and atomic numbering schemes of the ordered molecule 4 and the related $\mathrm{Se}^{\mathrm{II}} / \mathrm{Se}^{\mathrm{II}}$ system $\mathrm{ClSeN}(t \mathrm{Bu}) \mathrm{SeCl}(\mathbf{1})$ are shown in Figure 1 (the complete asymmetric unit is shown in Figure S1, Supporting Information) and bond lengths are compared with the PBE0/def2-TZVPP optimized values. Selected bond parameters for 1 and 4 are juxtaposed in Table S1(Supporting Information) and the corresponding data for the disordered pair in 4 can be found in Table S2 (Supporting Information).
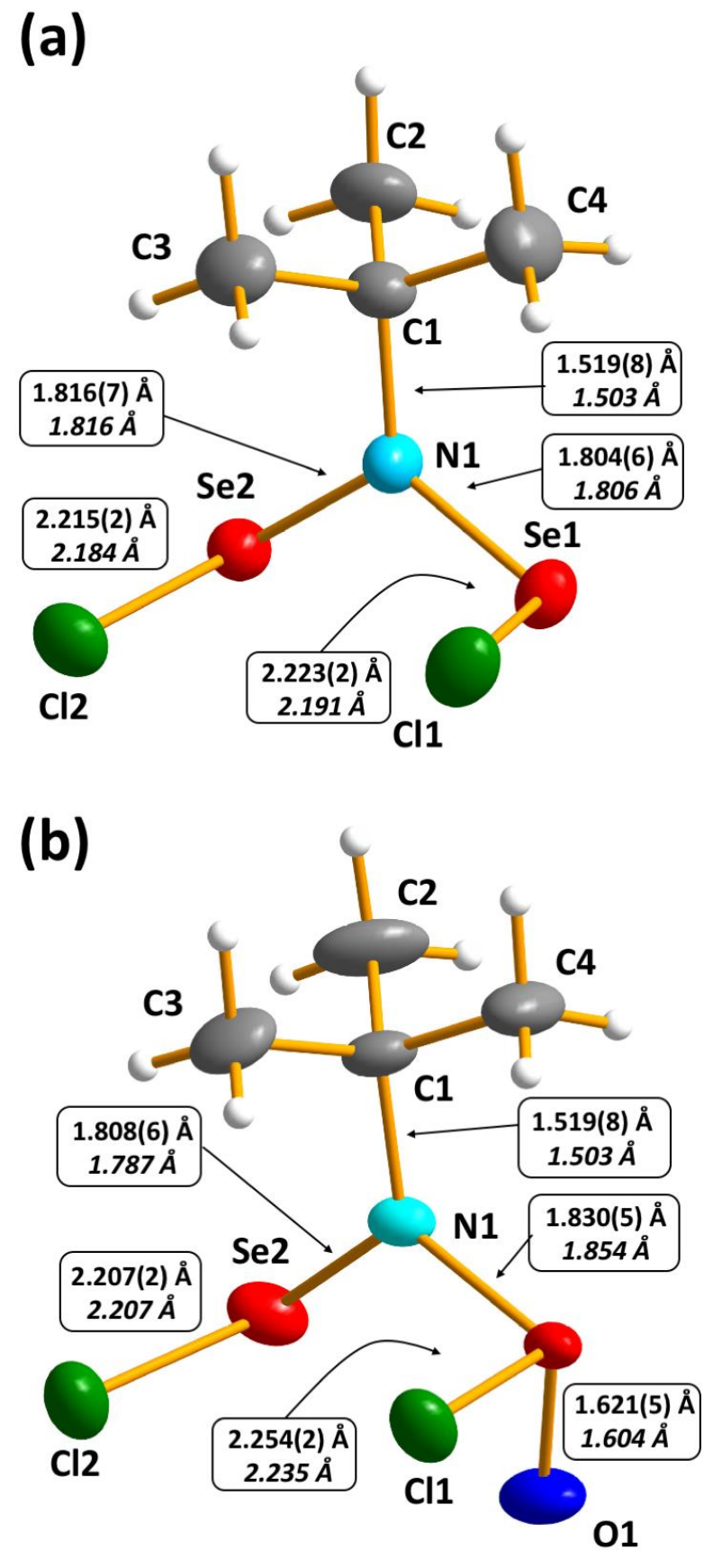

Figure 1. The structures of (a) 1 and (b) the ordered $\mathrm{ClSeN}(t \mathrm{Bu}) \mathrm{Se}(\mathrm{O}) \mathrm{Cl}$ molecule in the asymmetric unit of 4 . The metrical values in the upright font are experimental bond lengths from the crystal structure determination, and those in italics are computed values at PBE0/def2-TZVPP level of theory. The experimental values for $\mathrm{ClSeN}(t \mathrm{Bu}) \mathrm{SeCl}(1)$ were taken from Ref. 7a. The thermal ellipsoids are drawn at the $50 \%$ probability level. 
Table 1. Crystal data and structure refinement for 4 .

\begin{tabular}{|c|c|}
\hline Formula & $\mathrm{C}_{4} \mathrm{H}_{9} \mathrm{Cl}_{2} \mathrm{NOSe}$ \\
\hline$M_{r}$ & 315.94 \\
\hline Crystal size /mm & $0.20 \times 0.15 \times 0.12$ \\
\hline Crystal system & triclinic \\
\hline Space group & $P-1$ \\
\hline$a / \AA$ & $6.9820(14)$ \\
\hline$b / \AA$ & $11.235(2)$ \\
\hline$c / \AA$ & $12.957(3)$ \\
\hline$\alpha /{ }^{\circ}$ & $93.57(3)$ \\
\hline$\beta /{ }^{\circ}$ & $104.42(3)$ \\
\hline$\gamma /{ }^{\circ}$ & $98.47(3)$ \\
\hline$V / \AA^{3}$ & $968.5(4)$ \\
\hline$Z$ & 4 \\
\hline$D_{\text {calcd. }} / \mathrm{g} \cdot \mathrm{cm}^{-3}$ & 2.167 \\
\hline$\mu(\mathrm{Mo}-\mathrm{Ka})^{\text {a) }} / \mathrm{mm}^{-1}$ & 8.128 \\
\hline$F(000)$ & 600 \\
\hline$h k l$ range & $-8-(+8),-13-(+13),-15-(+15)$ \\
\hline$\theta$ range $/^{\circ}$ & $3.056-25.996$ \\
\hline Reflections measured & 11298 \\
\hline Reflections unique & 3542 \\
\hline$R_{\text {int }}$ & 0.0557 \\
\hline No of parameters/restraints & $206 / 18$ \\
\hline$R_{1}[I \geq 2 \sigma(I)]^{\mathrm{b})}$ & 0.0499 \\
\hline$\left.w R 2(\text { all data })^{c}\right)$ & 0.1078 \\
\hline GoF on $F^{2}$ & 1.086 \\
\hline$\Delta \rho($ fin $)(\max / \min ) / e \cdot \AA^{-3}$ & $1.190 /-1.183$ \\
\hline
\end{tabular}

a) $\lambda(\mathrm{Mo}-K \alpha)=0.71073 \AA$. b) $R_{1}=\Sigma|| F_{\mathrm{o}}|-| F_{\mathrm{c}}|| / \Sigma\left|F_{\mathrm{o}}\right|$. c) $w R_{2}=\left[\Sigma w\left(F_{\mathrm{o}}^{2}-F_{\mathrm{c}}^{2}\right)^{2} / \Sigma F_{0}^{4}\right]^{1 / 2}$.

The arrangement at the tricoordinate nitrogen atom in 4 is planar, $\Sigma[\operatorname{angles}(\mathrm{N})]=359.6^{\circ}(\mathrm{cf}$. $359.7^{\circ}$ in 1)..$^{[7]}$ Surprisingly, the presence of the $\mathrm{Se}^{\mathrm{IV}}$ atom in the former has little effect on the orientation of the two $\mathrm{Cl}$ substituents with respect to the SeNSe plane, as indicated by the similarity in the ClSeNSe torsion angles for 4 and 1 (Table S1). However, significant disparities are evident in the bond lengths. Thus, the Se1-N1 distance in 4 is ca. $0.02 \AA$ longer than the mean value in 1. Similarly, the Se1-Cl1 bond length of 2.254(2) $\AA$ in 4 is notably longer (by $0.035 \AA$ ) than the mean Se-Cl distance in 1; it is also ca. $0.05 \AA$ A longer than the Se2-Cl2 bond length involving the two-coordinate Se atom in 4. As expected, the $\mathrm{Cl}-\mathrm{Se}-\mathrm{N}$ bond angle involving the three-coordinate Se atom in 4 is ca. $4^{\circ}$ narrower than the corresponding bond angles in 1 .

The PBE0/def2-TZVPP optimized geometries of both 1 and 4 are in good agreement with observed metrical parameters (see Figure 1) and indicate that the differences in the bond lengths are due to intramolecular electronic effects rather than intermolecular interactions in the solid state. In previous work, we have shown that negative hyperconjugation plays a significant role in explaining the trends in $\mathrm{Se}-\mathrm{N}$ and $\mathrm{Se}-\mathrm{Cl}$ bond lengths, as well as the intramolecular $\mathrm{Se} \cdots \mathrm{Se}$ interaction, in the $\mathrm{Se}{ }^{\mathrm{II}} / \mathrm{Se}^{\mathrm{II}}$ chain molecules 2 and 
3. ${ }^{[7 a, 8]}$ The present PBE0/def2-TZVPP NBO analysis showed that hyperconjugative interactions are also significant in explaining the structural differences between the $\mathrm{Se}^{\mathrm{II}} / \mathrm{Se}^{\mathrm{II}}$ system 1 and the $\mathrm{Se}^{\mathrm{II}} / \mathrm{Se}^{\mathrm{IV}}$ system 4 (see Figure 2).

The most important interaction energies in 4 are $n^{2}(\mathrm{O}) \rightarrow \sigma^{*}(\mathrm{Se}-\mathrm{Cl})$ and $\mathrm{n}^{2}(\mathrm{O}) \rightarrow \sigma^{*}(\mathrm{Se}-\mathrm{N})$. The $\mathrm{Se}=\mathrm{O}$ bond length in 4 is short [1.621(5) $\AA$, cf. values of 1.621(2) $\AA$ and 1.628(4) $\AA$ found for the imidooxo $\mathrm{Se}^{\mathrm{IV}} / \mathrm{Se}^{\mathrm{IV}}$ systems $\mathrm{OSe}(\mu-\mathrm{N} t \mathrm{Bu})_{2} \mathrm{SeO}{ }^{[14]}$ and $t \mathrm{BuNSe}(\mu-\mathrm{N} t \mathrm{Bu})_{2} \mathrm{SeO},{ }^{[7 b]}$ respectively]. It can also be compared with the selenium-oxygen bond lengths of 1.621-1.701 $\AA$, 1.638-1.653 $\AA$, and 1.571-1.616 $\mathrm{An}$ the $\mathrm{C}_{2} \mathrm{SeO}, \mathrm{C}(\mathrm{N}) \mathrm{SeO}$, and $\mathrm{Cl}_{2} \mathrm{SeO}$ moieties, respectively. ${ }^{[15]}$ It can clearly be seen that the $\mathrm{n}^{2}(\mathrm{O}) \rightarrow$ $\sigma^{*}(\mathrm{Se}-E)(E=\mathrm{C}, \mathrm{N}, \mathrm{Cl})$ becomes more significant as the electronegativity of the $E$ atom increases. Consequently, the $\mathrm{SeO}$ bond shortens and its bond order increases. At the same time, the bond order of the Se-E bond expectedly decreases.

The $\mathrm{n}^{2}(\mathrm{~N}) \rightarrow \sigma^{*}(\mathrm{Se}-\mathrm{N})$ interaction energies are approximately equal in $\mathbf{1}$ and $\mathbf{4}$.

(a)

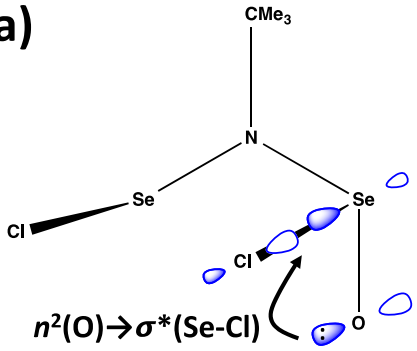

$38 \mathrm{~kJ} \mathrm{~mol}^{-1}$

(c)

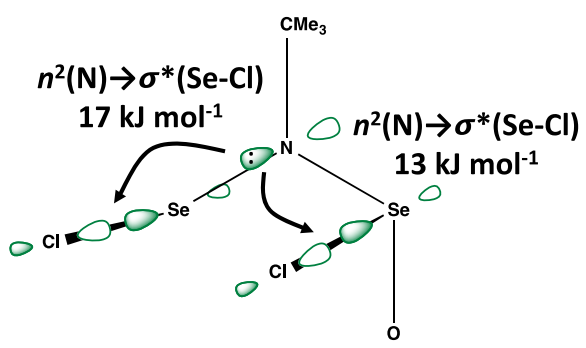

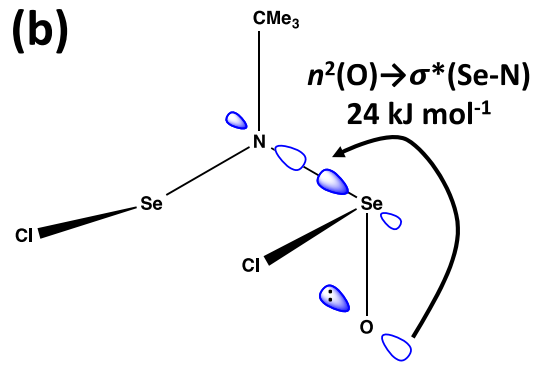

(d)

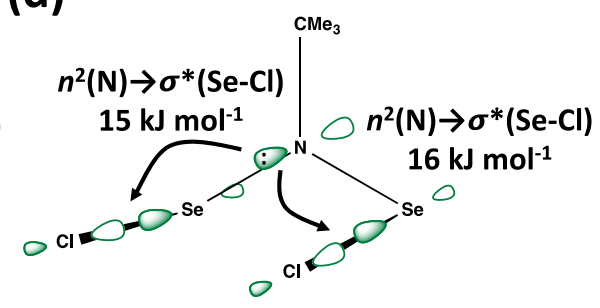

Figure 2. Negative hyperconjugation based on PBE0/def2-TZVPP NBO interaction energies: (a) $\mathrm{n}^{2}(\mathrm{O}) \rightarrow \sigma^{*}(\mathrm{Se}-\mathrm{Cl})$, (b) $\mathrm{n}^{2}(\mathrm{O}) \rightarrow \sigma^{*}(\mathrm{Se}-\mathrm{N})$, and $(\mathrm{c}) \mathrm{n}^{2}(\mathrm{~N}) \rightarrow \sigma^{*}(\mathrm{Se}-\mathrm{Cl})$ interaction in $\mathrm{ClSe}(\mathrm{NtBu}) \mathrm{Se}(\mathrm{O}) \mathrm{Cl}(4)$, and $(\mathrm{d}) \mathrm{n}^{2}(\mathrm{~N}) \rightarrow \sigma^{*}(\mathrm{Se}-\mathrm{Cl})$ interactions in $\mathrm{ClSe}(\mathrm{NtBu}) \mathrm{SeCl}(\mathbf{1})$.

\section{Energetics of the Formation of 4}

In a recent contribution we calculated the energetics of the reactions of $t \mathrm{BuNH}_{2}$ with $\mathrm{SeCl}_{2}$ in $\mathrm{THF}$ at the PBE0/def2-TZVPP level of theory and found that the sequential formation of the series of 
imidoselenium(II) chlorides $\mathrm{ClSe}[\mathrm{N}(t \mathrm{Bu}) \mathrm{Se}]_{n} \mathrm{Cl}[n=1(1), n=2(2), n=3$ (3)] is energetically favorable. ${ }^{[8]}$ Based on the reaction profile reported therein, the formation of 4 by treatment of $t \mathrm{BuNH}_{2}$ with a mixture of $\mathrm{SeCl}_{2}$ and $\mathrm{SeOCl}_{2}$ [Equation (1)] can be envisaged to follow either of two alternative routes [Equation (2) and Equation (3), or Equation (4) and Equation (5)] that are depicted in Figure 3.

$$
\begin{aligned}
& \mathrm{SeCl}_{2}+2 t \mathrm{BuNH}_{2} \rightarrow t \mathrm{BuN}(\mathrm{H}) \mathrm{SeCl}+\left(t \mathrm{BuNH}{ }_{3}\right) \mathrm{Cl}(\mathrm{s}) \\
& t \mathrm{BuNH}_{2}+t \mathrm{BuN}(\mathrm{H}) \mathrm{SeCl}+\mathrm{SeOCl}_{2} \rightarrow \mathrm{ClSeN}(t \mathrm{Bu}) \mathrm{Se}(\mathrm{O}) \mathrm{Cl}+\left(t \mathrm{BuNH}_{3}\right) \mathrm{Cl}(\mathrm{s}) \\
& \mathrm{SeOCl}_{2}+2 t \mathrm{BuNH}_{2} \rightarrow t \mathrm{BuN}(\mathrm{H}) \mathrm{Se}(\mathrm{O}) \mathrm{Cl}+\left(t \mathrm{BuNH}{ }_{3}\right) \mathrm{Cl}(\mathrm{s}) \\
& t \mathrm{BuNH}_{2}+t \mathrm{BuN}(\mathrm{H}) \mathrm{Se}(\mathrm{O}) \mathrm{Cl}+\mathrm{SeCl}_{2} \rightarrow \mathrm{ClSeN}(t \mathrm{Bu}) \mathrm{Se}(\mathrm{O}) \mathrm{Cl}+\left(t \mathrm{BuNH}_{3}\right) \mathrm{Cl}(\mathrm{s})
\end{aligned}
$$

In a manner similar to the formation of $\mathrm{ClSe}(\mathrm{NtBu}) \mathrm{SeCl}(1)$ from $\mathrm{SeCl}_{2}$ and $t \mathrm{BuNH}_{2},{ }^{[8]}$ both reaction profiles contain intermediate products lying in local minima and two transition states each displaying only a single imaginary frequency with respect to the reaction coordinate. In the case of route depicted in Equations (2) and (3), (Figure 3a), the first step is the interaction of $\mathrm{SeCl}_{2}$ with $t \mathrm{BuNH}_{2}$, as described previously. ${ }^{[8]}$ After the initial adduct formation between $t \mathrm{BuNH}_{2}$ and $\mathrm{SeCl}_{2}$, this intermediate interacts with another amine molecule leading to proton transfer via the transition state TS11 and the formation of $t \mathrm{BuN}(\mathrm{H}) \mathrm{SeCl}$ with the precipitation of solid $\left(t \mathrm{BuNH}_{3}\right) \mathrm{Cl}$. The intermediate $t \mathrm{BuN}(\mathrm{H}) \mathrm{SeCl}$ then interacts with another amine molecule and $\mathrm{SeOCl}_{2}$ to give $\mathrm{ClSeN}(t \mathrm{Bu}) \mathrm{Se}(\mathrm{O}) \mathrm{Cl}(4)$ and $\left(t \mathrm{BuNH}_{3}\right) \mathrm{Cl}(\mathrm{s})$ via TS12. Similar to the formation of $\mathrm{ClSe}(\mathrm{N} t \mathrm{Bu}) \mathrm{SeCl}(1),{ }^{[8]}$ the activation energies for the transition states TS11 and TS12 are reasonably low and the driving force for this reaction is the formation of $\left(t \mathrm{BuNH}_{3}\right) \mathrm{Cl}(\mathrm{s})$.

In the case of the alternative route depicted in Equations (4) and (5), (Figure 3b), the first step involves the interaction of $\mathrm{SeOCl}_{2}$ with $t \mathrm{BuNH}_{2}$ with the formation of $t \mathrm{BuN}(\mathrm{H}) \mathrm{Se}(\mathrm{O}) \mathrm{Cl}$ and $\left.(t \mathrm{BuNH})_{3}\right) \mathrm{Cl}(\mathrm{s})$ via the transition state TS21. The second step entails the interaction of this intermediate with $\mathrm{SeCl}_{2}$ and $t \mathrm{BuNH}_{2}$ via the transition state $T S 22$ and leads to the final product 4 and the precipitation of $\left(t \mathrm{BuNH}_{3}\right) \mathrm{Cl}(\mathrm{s})$. It can be seen from Figure 3 that the two alternative pathways yield very similar energetics and the reaction can proceed by either route. 

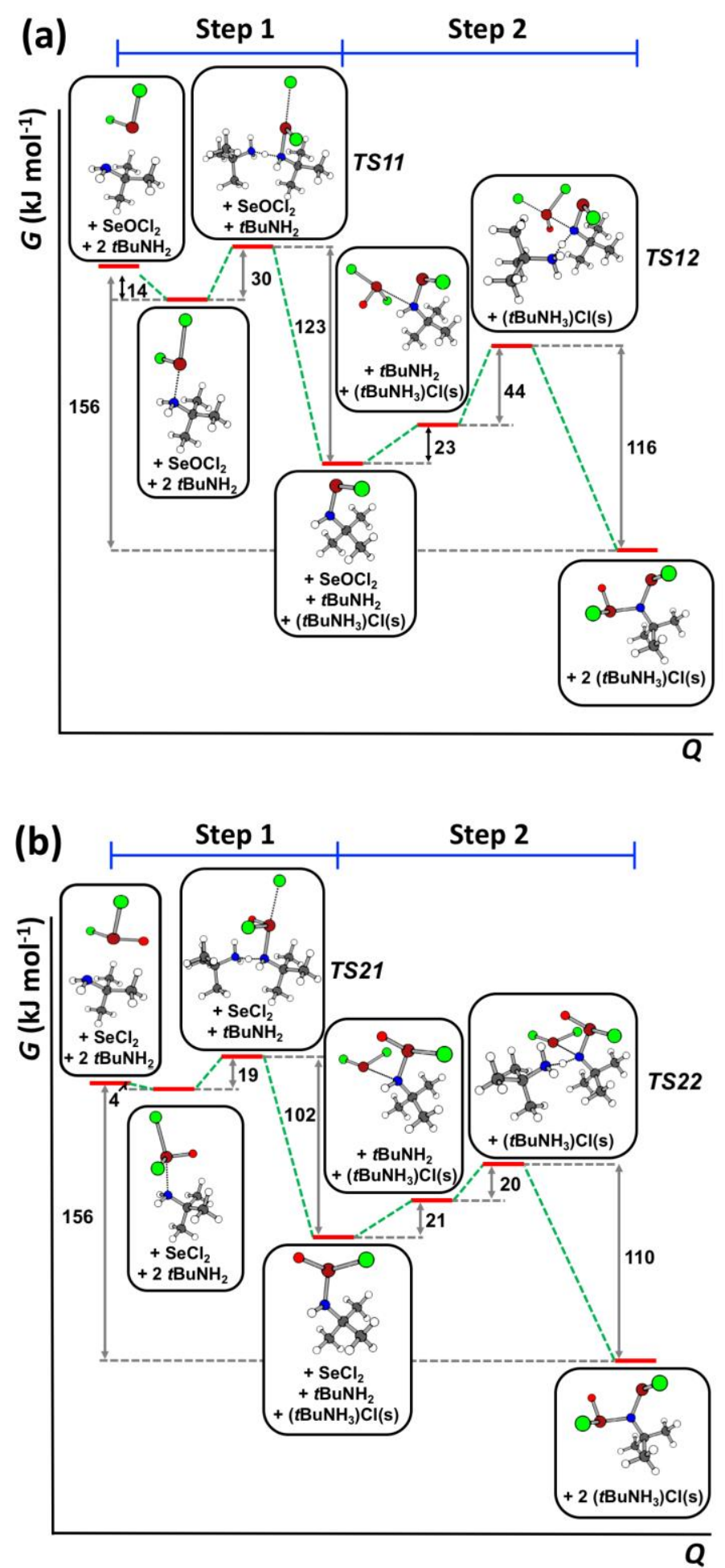

Figure 3. PBE0/def2-TZVPP energy profiles for the formation of $\mathrm{ClSeN}(t \mathrm{Bu}) \mathrm{Se}(\mathrm{O}) \mathrm{Cl}(4)$ from the reaction of $t \mathrm{BuNH} \mathrm{H}_{2}$ with a mixture of $\mathrm{SeCl}_{2}$ and $\mathrm{SeOCl}_{2}$ assuming that (a) the reagent $\mathrm{SeCl}_{2}$ and (b) the reagent $\mathrm{SeOCl}_{2}$ is involved in the first step. Energies are given in $\mathrm{kJ} \mathrm{mol}^{-1}$.

\section{CONCLUSIONS}

We have developed a convenient synthesis of $\mathrm{ClSeN}(t \mathrm{Bu}) \mathrm{Se}(\mathrm{O}) \mathrm{Cl}(4)$, an unique selenium-nitrogen chain with selenium centres in two different oxidation states for which there is no sulfur analogue. The 
small structural differences between the $\mathrm{Se}^{\mathrm{II}} / \mathrm{Se}^{\mathrm{IV}}$ system 4 and the related $\mathrm{Se}^{\mathrm{II}} / \mathrm{Se}^{\mathrm{II}}$ molecule $\mathrm{ClSeN}(t \mathrm{Bu}) \mathrm{SeCl}(\mathbf{1})$ are attributed primarily to the effects of negative hyperconjugation. Calculations of the energetics of the reaction of $t \mathrm{BuNH}_{2}$ and a mixture of $\mathrm{SeCl}_{2}$ and $\mathrm{SeOCl}_{2}$ show that the formation of 4 is strongly favoured regardless of whether the first step involves $\mathrm{SeCl}_{2}$ and $\mathrm{SeOCl}_{2}$. In view of the key role of 1-3 as intermediates in the formation of cyclic selenium imides, ${ }^{[8]}$ the bifunctional character of 4 renders it a potentially versatile reagent for the development of selenium-nitrogen chemistry involving selenium in different oxidation states.

\section{EXPERIMENTAL SECTION}

\section{General Procedures}

All reactions and manipulations of air- and moisture-sensitive compounds were carried out under an inert atmosphere by using a standard drybox or Schlenk techniques. Tetrahydrofuran and toluene were dried by distillation over $\mathrm{Na}$ /benzophenone in an argon atmosphere prior to use. Selenium granules (Merck), $\mathrm{SO}_{2} \mathrm{Cl}_{2}$ (Aldrich), and $\mathrm{SeOCl}_{2}$ (Aldrich) were used as purchased. $t \mathrm{BuNH}_{2}$ (Aldrich) was distilled over $\mathrm{KOH}$ and stored over molecular sieves. $\mathrm{SeCl}_{2}$ was prepared from freshly ground selenium and $\mathrm{SO}_{2} \mathrm{Cl}_{2}$ in THF by the literature procedure. ${ }^{[10]}$

\section{NMR Spectroscopy}

The ${ }^{1} \mathrm{H},{ }^{13} \mathrm{C}\left\{{ }^{1} \mathrm{H}\right\}$, and ${ }^{77} \mathrm{Se}$ NMR spectra were recorded with a Bruker Avance III spectrometer operating at 400.13, 100.62, and 76.31 MHz, respectively. Typical spectral widths were 8.22, 24.04, and $113.64 \mathrm{kHz}$, and the pulse widths were $26.50,14.30$, and $16.75 \mu$ s. The pulse delays for proton, carbon, and selenium were 1.0, 2.0, and $1.0 \mathrm{~s}$, respectively. The ${ }^{1} \mathrm{H}$ and ${ }^{13} \mathrm{C}\left\{{ }^{1} \mathrm{H}\right\}$ NMR spectra were referenced to the solvent resonances and are reported relative to $\mathrm{Me}_{4} \mathrm{Si}$. $\left[\mathrm{D}_{8}\right]$ Toluene was used as a ${ }^{2} \mathrm{H}$ lock. The ${ }^{77} \mathrm{Se} \mathrm{NMR}$ spectra were referenced externally to a saturated aqueous solution of selenium dioxide, and the chemical shifts are reported relatively to neat $\mathrm{Me}_{2} \mathrm{Se}\left[\delta\left(\mathrm{Me}_{2} \mathrm{Se}\right)=\delta\left(\mathrm{SeO}_{2}\right)+1302.6\right] .{ }^{[16]}$

\section{Preparation of $\mathrm{ClSeN}(\mathrm{tBu}) \mathrm{Se}(\mathrm{O}) \mathrm{Cl}(4)$}

A mixture of $\mathrm{SeCl}_{2}(8.0 \mathrm{mmol})^{[10]}$ and $\mathrm{SeOCl}_{2}(0.27 \mathrm{~mL}, 4.0 \mathrm{mmol})$ in THF $(5 \mathrm{~mL})$ was added dropwise to a solution of $t \mathrm{BuNH}_{2}(2.5 \mathrm{~mL}, 23.8 \mathrm{mmol})$ in THF $(45 \mathrm{~mL})$ at $-80^{\circ} \mathrm{C}$. The reaction mixture was stirred for $30 \mathrm{~min}$ at $-80{ }^{\circ} \mathrm{C}$ and for further $1.5 \mathrm{~h}$ at room temperature. The precipitate of $\left(t \mathrm{BuNH}_{3}\right) \mathrm{Cl}$ was removed by filtration and solvent was evaporated under a dynamic vacuum to give a reddish-brown oil, which was extracted with toluene $(25 \mathrm{~mL})$. The toluene solution was cooled to $-20{ }^{\circ} \mathrm{C}$ to give air- and 
temperature-sensitive orange-yellow crystals of 4 ( $0.680 \mathrm{~g}, 2.15 \mathrm{mmol}$; yield based on $\mathrm{SeOCl}_{2} 54 \%$ ). Anal. Calcd. for $\mathrm{C}_{4} \mathrm{H}_{9} \mathrm{Cl}_{2} \mathrm{NOSe}_{2}$ : C, 15.21; H, 2.87; N, 4.43 \%. Found: C, 15.81; H, 3.17; N, 4.97 \%. ${ }^{1} \mathrm{H}$ NMR $\left(400.13 \mathrm{MHz}, \mathrm{C}_{7} \mathrm{D}_{8}, 25^{\circ} \mathrm{C}\right): \delta=1.29 ;{ }^{13} \mathrm{C}\left\{{ }^{1} \mathrm{H}\right\} \mathrm{NMR}\left(100.62 \mathrm{MHz}, \mathrm{C}_{7} \mathrm{D}_{8}, 25{ }^{\circ} \mathrm{C}\right): \delta=72.1\left[-C\left(\mathrm{CH}_{3}\right)_{3}\right]$, $31.3\left[-\mathrm{C}\left(\mathrm{CH}_{3}\right)_{3}\right] ;{ }^{77} \mathrm{Se} \mathrm{NMR}\left(76.31 \mathrm{MHz}, \mathrm{C}_{7} \mathrm{D}_{8}, 25{ }^{\circ} \mathrm{C}\right): \delta=1435[\mathrm{NSe}(=\mathrm{O}) \mathrm{Cl}], 1291(\mathrm{NSeCl}) ; \delta^{77} \mathrm{Se}$ $\left(\mathrm{THF}, 25^{\circ} \mathrm{C}\right): 1447[\mathrm{NSe}(=\mathrm{O}) \mathrm{Cl}], 1316(\mathrm{NSeCl})$.

\section{X-Ray Crystallography}

$\mathrm{X}$-ray quality crystals were grown from a toluene solution at $-20{ }^{\circ} \mathrm{C}$. Diffraction data for compound 4 were collected at 120(2) K on a Nonius Kappa CCD diffractometer using graphite-monochromated Mo- $\mathrm{K}_{\alpha}$ radiation $(\lambda=0.71073 \AA)$. The structure was solved by direct methods using SHELXS-2013 and refined using SHELXL-2013. ${ }^{[17]}$ After the full-matrix least-squares refinement of the non-hydrogen atoms with anisotropic thermal parameters, the hydrogen atoms were placed in calculated positions in the methyl groups $(\mathrm{C}-\mathrm{H}=0.98 \AA$ ). In the final refinement the hydrogen atoms were riding with the carbon atom they were bonded to. The isotropic thermal parameters of the hydrogen atoms were fixed at 1.5 times to that of the corresponding carbon. The scattering factors for the neutral atoms were those incorporated with the program.

One of the two $\mathrm{ClSeN}(t \mathrm{Bu}) \mathrm{Se}(\mathrm{O}) \mathrm{Cl}(4)$ molecules in the asymmetric unit was disordered assuming statistically two different orientations. The disorder was resolved by constraining the asymmetric displacement parameters of the corresponding atoms in the disordered pair equal, applying slight restraints on the bond lengths, and refining the site occupation factors together with the positional and common anisotropic thermal parameters. The final refined site occupational factors of the two orientations were $0.564(4)$ and $0.436(4)$. The complete asymmetric unit in the crystal structure of 4 together with the numbering of the atoms is shown in Figure S1 (Supporting Information).

Crystallographic data (excluding structure factors) for the structure in this paper have been deposited with the Cambridge Crystallographic Data Centre, CCDC, 12 Union Road, Cambridge CB21EZ, UK. Copies of the data can be obtained free of charge on quoting the depository number CCDC-1522803 (4) (Fax: +44-1223-336-033; E-Mail: deposit@ccdc.cam.ac.uk, http://www.ccdc.cam.ac.uk).

\section{Computational Details}

The calculations were performed on Gaussian 09 program ${ }^{[18]}$ by employing the PBE0 hybrid functional ${ }^{[19]}$ and def2-TZVPP basis sets. ${ }^{[20,21]}$ Dispersion forces were treated by using D3BJ version of Grimme's empirical correction with Becke-Johnson damping parameterized for PBE0 functional. ${ }^{[22]}$ Full geometry 
optimization was carried out for each species and the frequencies were calculated for the optimum geometries to ascertain the nature of the stationary points. Energies in THF and toluene were calculated using CPCM method implemented in Gaussian 09. ${ }^{[23]}$ Nuclear magnetic shielding tensors were calculated using GIAO method. ${ }^{[24]}$ The ${ }^{77} \mathrm{Se}$ chemical shifts were calculated using the calibration described previously. ${ }^{[13]}$

The contribution of the precipitation of $\left(t \mathrm{BuNH}_{3}\right) \mathrm{Cl}$ to the energetics of the reactions was estimated by computing the energy of formation of the ion-pair $t \mathrm{BuNH}_{3}{ }^{+}$and $\mathrm{Cl}^{-}$and correcting the energy for lattice effects by involving solid-state DFT calculations, which utilize the periodic boundary conditions. Optimizations and frequency calculations for the $\left(t \mathrm{BuNH}_{3}\right) \mathrm{Cl}$ sublimation energy estimations were performed with Crystal14 program ${ }^{[25]}$ using the PBE0 functional ${ }^{[26]}$ and pob-TZVPP basis set ${ }^{[25]}$ (for computational details, see Ref. 8).

Natural bond orbital (NBO) method ${ }^{[27]}$ was used to study donor-acceptor interactions in the gas-phase optimized geometries. NBO analyses were carried out using the NBO 5.9 software. ${ }^{[28]}$

\section{ACKNOWLEDGEMENTS}

Financial support from Academy of Finland [grant numbers 134548 (R. S. L.) and 253400 (J. M. R)], Finnish Cultural Foundation (A. J. K.), Magnus Ehrnrooth Foundation (A. J. K.), Oulu University Scholarship Foundation (A. J. K.) and the Natural Sciences and Engineering Research Council (NSERC, Canada) (T. C.) is gratefully acknowledged. We are also grateful to Finnish CSC-IT Center for Science Ltd for their provision of computational resources.

Supporting Information (see footnote on the first page of this article): Molecular structure and the list of selected bond parameters of 4 .

\section{REFERENCES}

[1] T. Chivers, A Guide to Chalcogen-Nitrogen Chemistry, World Scientific Co. Pt. Ltd., Singapore, 2005.

[2] J. D. Woollins, Non-Metal Rings, Cages and Clusters, John Wiley \& Sons, Chichester, U.K., 1998.

[3] (a) O. Glemser, B. Krebs, J. Wegener, E. Kindler, Angew. Chem., Int. Ed. Engl., 1969, 8, 598. (b) O. Glemser, E. Kindler, B. Krebs, R. Mews, Z. Naturforsch.,1980, 35b, 657-660.

[4] (a) R. Wollert, A. Hollwarth, G. Frenking, D. Fenske, H. Goesman, K. Dehnicke, Angew. Chem., Int. Ed. Engl., 1992, 31, 1251-1253. (b) M. Broschag, T. M. Klapötke, A. Schulz, P. S. White, Inorg. Chem., 1993, 32, 5734-5738. (c) M. Broschag, T. M. Klapötke, A. Schulz, P. S. White, Chem. Ber., 1994, 127, 2177-2179. 
[5] (a) M. Broschag, T. M. Klapötke, I. C. Tornieporth-Oetting, P. S. White, J. Chem. Soc., Chem. Comm., 1992, 1390-1391. (b) A. Schulz, M. Broschag, I. C. Tornieporth-Oetting, T. M. Klapötke, P. Buzek, P. von R. Schleyer, P. S. White, Chem. Ber., 1995, 128, 35-40.

[6] C. Lau, B. Neumüller, S. F. Vyboishchikov, G. Frenking, K. Dehnicke, W. Hiller, M. Herker, Chem. Eur. J., 1996, 2, 1373-1378.

[7] (a) T. Maaninen, T. Chivers, R. Laitinen, E. Wegelius, Chem. Commun., 2000, 759-760. (b) T. Maaninen, T. Chivers, R. Laitinen, G. Schatte, M. Nissinen, Inorg. Chem., 2000, 39, 5341-5347.

[8] A. J. Karhu, O. J. Pakkanen, J. M. Rautiainen, R. Oilunkaniemi, T. Chivers, R. S. Laitinen, Dalton Trans., 2016, 45, 6210-6221.

[9] For a review, see T. Chivers, R. S. Laitinen, Dalton Trans., 2017, 46, 1357-1367.

[10] A. Maaninen, T. Chivers, M. Parvez, J. Pietikainen, R. S. Laitinen, Inorg. Chem., 1999, 38, 4093-4097.

[11] This yield should be viewed in the context of the known tendency of secondary amines to reduce Se $\mathrm{IV}^{\mathrm{IV}}$ to $\mathrm{Se}^{\mathrm{II}}$ in reactions with $\mathrm{SeOCl}_{2}$. R. B. King, S. A. Sangokoya, Inorg. Chem. 1987, 26, 2727-2730.

[12] The reaction of $\mathrm{SeOCl}_{2}$ with the primary amine equivalent $t \mathrm{BuN}(\mathrm{Li}) \mathrm{SiMe}_{3}$ produces cyclic selenium imides, $\mathrm{Se}_{6}(\mathrm{~N} t \mathrm{Bu})_{2}$ and $\mathrm{Se}_{9}(\mathrm{~N} t \mathrm{Bu})_{6}$, respectively. H. W. Roesky, K. L. Weber, J. W. Bats, Chem. Ber., 1984, $117,2686-2692$.

[13] A. J. Karhu, O. J. Pakkanen, J. M. Rautiainen, R. Oilunkaniemi, T. Chivers, R. S. Laitinen, Inorg. Chem., 2015, 54, 4990-4997.

[14] T. Maaninen, R. Laitinen, T. Chivers, Chem. Commun., 2002, 1812-1813.

[15] Conquest 1.19, Cambridge Crystallographic Data Center, Cambridge 2016.

[16] R. C. Burns, M. J. Collins, R. J. Gillespie, G. J. Schrobilgen, Inorg. Chem., 1986, 25, 4465-4469.

[17] G. M. Sheldrick, Acta Crystallogr., 2008, 64A, 112-122.

[18] Gaussian 09, Revision D.01, M. J. Frisch, G. W. Trucks, H. B. Schlegel, G. E. Scuseria, M. A. Robb, J. R. Cheeseman, G. Scalmani, V. Barone, B. Mennucci, G. A. Petersson, H. Nakatsuji, M. Caricato, X. Li, H. P. Hratchian, A. F. Izmaylov, J. Bloino, G. Zheng, J. L. Sonnenberg, M. Hada, M. Ehara, K. Toyota, R. Fukuda, J. Hasegawa, M. Ishida, T. Nakajima, Y. Honda, O. Kitao, H. Nakai, T. Vreven, J. A. Montgomery Jr., J. E. Peralta, F. Ogliaro, M. Bearpark, J. J. Heyd, E. Brothers, K. N. Kudin, V. N. Staroverov, R. Kobayashi, J. Normand, K. Raghavachari, A. Rendell, J. C. Burant, S. S. Iyengar, J. Tomasi, M. Cossi, N. Rega, M. J. Millam, M. Klene, J. E. Knox, J. B. Cross, V. Bakken, C. Adamo, J.Jaramillo, R. Gomperts, R. E. Stratmann, O. Yazyev, A. J. Austin, R. Cammi, C. Pomelli, J. W. Ochterski, R. L. Martin, K. Morokuma, V. G. Zakrzewski, G. A. Voth, P. Salvador, J. J. Dannenberg, S. Dapprich, A. D. Daniels, Ö.; Farkas, J. B. Foresman, J. V. Ortiz, J. Cioslowski, D. J. Fox, Gaussian, Inc., Wallingford, CT, USA, 2013.

[19] (a) J. P. Perdew, K. Burke, M. Ernzerhof, Phys. Rev. Lett., 1996, 77, 3865-3868. (b) J. P. Perdew, K. Burke, M. Ernzerhof, Phys. Rev. Lett., 1997, 78, 1396. (c) J. P. Perdew, M. Ernzerhof, K. Burke, J. Chem. Phys. 1996, 105, 9982-9985. (d) C. Adamo, V. Barone, J. Chem. Phys., 1999, 110, 6158-6170.

[20] (a) F. Weigend, R. Ahlrichs, Phys. Chem. Chem. Phys., 2005, 7, 3297-3305. (b) D. Andrae, U. Häußermann, M Dolg, H Stoll, H. Preuß, Theor. Chim. Acta 1990, 77, 123-141.

[21] EMSL basis set library https://bse.pnl.gov/bse/portal.

[22] S. Grimme, S. Ehrlich, L. Goerigk, J. Comp. Chem., 2011, 32, 1456-1465.

[23] (a) V. Barone, M. Cossi, J. Phys. Chem. A, 1998, 102, 1995-2001. (b) M. Cossi, N. Rega, G. Scalmani, V. Barone, J. Comp. Chem., 2003, 24, 669-681.

[24] (a) R. McWeeny, Phys. Rev., 1962, 126, 1028-1034. (b) R. Ditchfield, Mol. Phys., 1974, 27, 789-807. (c) K. Wolinski, J. F. Hilton, P. Pulay, J. Am. Chem. Soc., 1990, 112, 8251-8260. (d) J. R. Cheeseman, G. W. Trucks, T. A. Keith, M. J. Frisch, J. Chem. Phys., 1996, 104, 5497-5509.

[25] (a) R. Dovesi, R. Orlando, A. Erba, C. M. Zicovich-Wilson, B. Civalleri, S. Casassa, L. Maschio, M. Ferrabone, M. De La Pierre, P. D’Arco, Y. Noel, M. Causa, M. Rerat, B. Kirtman Int. J. Quantum Chem. 2014, 114, 1287-1317. (b) R. Dovesi, V. R. Saunders, C. Roetti, R. Orlando, C. M. Zicovich-Wilson, F. Pascale, B. Civalleri, K. Doll, N. M. Harrison, I. J. Bush, P. D’Arco, M. Llunell, M. Causà, Y. Noël CRYSTAL14, CRYSTAL14 User's Manual, University of Torino, Torino, Italy, 2014.

[26] M. F. Peintinger, D. Vilela Oliveira, and T. Bredow, J. Comput. Chem., 2012, 34, 451-459.

[27] (a) A. E. Reed, R. B. Weinstock and F. Weinhold, J. Chem. Phys., 1985, 83, 735-746. (b) E. D. Glendening, C. R. Landis and F. Weinhold, WIREs Comput. Mol. Sci., 2012, 2, 1-42. (c) F. Weinhold, J. Comput. Chem., 2012, 33, 2363-2379.

[28] NBO 5.9. E. D. Glendening, J. K. Badenhoop, A. E. Reed, J. E. Carpenter, J. A. Bohmann, C. M. Morales, F. Weinhold (Theoretical Chemistry Institute, University of Wisconsin, Madison, WI, USA, 2012); http://www.chem.wisc.edu/ nbo5. 


\section{A Selenium-Nitrogen Chain with Selenium in Different Oxidation States}

Aino J. Karhu, Juho Jämsä, J. Mikko Rautiainen, Raija Oilunkaniemi, Tristram Chivers, and Risto

S. Laitinen

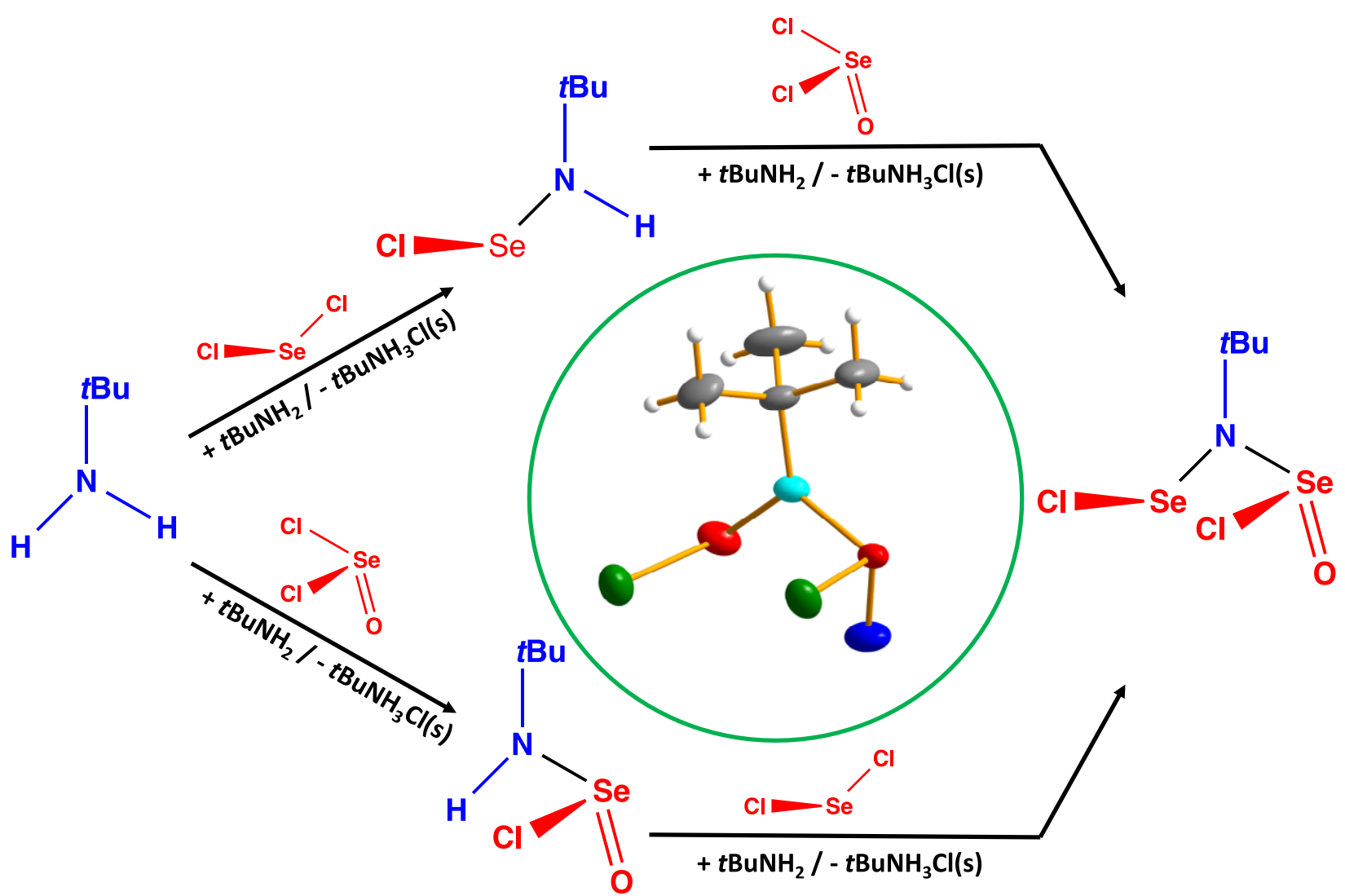

